\title{
Short-term results of suture treatment for pincer nail deformity
}

\author{
Nihat Demirhan Demirkıran, $\mathrm{MD}, \mathrm{PhD}^{1} \mathbb{0}$, Ramadan Özmanevra, $\mathrm{MD}^{2}$ (D) \\ ${ }^{1}$ Department of Orthopedics and Traumatology, Kütahya Health Sciences University, Kütahya, Turkey \\ ${ }^{2}$ Department of Orthopedics and Traumatology, University of Kyrenia Hospital, Kyrenia, Cyprus
}

Pincer nail deformity (PND) is a nail dystrophy characterized by over curvature of the nail plate along its longitudinal axis. Since it was first described as an inherited disorder over 40 years ago, several hereditary and acquired factors have been accused, although the main etiology for this deformity remains unclear. ${ }^{[1]}$ Mechanical factors such as narrow or high heeled shoes, foot deformities, tumors of the nail, phalanx osteoarthritis, fungal infections, beta blocker drugs and systemic diseases like Kawasaki's disease, renal failure and gastrointestinal malignancies have all been reported as acquired PND causes. ${ }^{[2-5]}$ Treatment of the underlying condition is also effective in reverting the deformity. Pincer nail deformity may be prevalent in as much as $1 \%$ of the whole population. ${ }^{[6]}$ Although all nails can be affected, the most common presentation is on big toe.

Several conservative and surgical methods have been developed to treat PND. Surgical methods including nail avulsion, total or partial nail bed excisions, phenol applications, electrocauterization, removal of osteophytes, dermal or mucosal skin grafting of the nail bed provide satisfactory longterm results. ${ }^{[-9]}$ However, these surgical treatment modalities may also have some complications including pain, secondary infections and the risk of

\footnotetext{
Received: August 26, 2019

Accepted: September 30, 2019

Published online: March 02, 2020
}

Correspondence: Ramadan Özmanevra, MD. Dr. Suat Günsel Girne Üniversitesi Hastanesi, Ortopedi ve Travmatoloji Kliniği, Karakum, 99320 Girne, Kuzey Kıbris.

E-mail: rozmanevra@gmail.com

Doi: $10.5606 /$ ehc. 2020.71133

Citation: Demirkıran ND, Özmanevra R. Short-term results of suture treatment for pincer nail deformity. Jt Dis Relat Surg 2020;31(1):43-49.

\section{ABSTRACT}

Objectives: This study aims to evaluate the cosmetic and functional results of suture treatment on pincer nail deformity (PND).

Patients and methods: This study was conducted between June 2018 and November 2018. Sixteen nails of 13 patients (6 males; 7 females; mean age 46.9 years; range, 24 to 74 years) with PND were treated with silk sutures. The pathologic stage (including tissue status and level of pain), visual analog scale (VAS), nail height $(\mathrm{H})$ and width $(\mathrm{W})$ were evaluated pre- and postoperatively. Nail $\mathrm{H}$ and $\mathrm{W}$ were measured pre- and postoperatively from digital photographs of each nail and H/W ratio was calculated.

Results: The postoperative VAS, severity of pain scores, and nail $\mathrm{H}$ showed a significant decrease compared to the preoperative values $(p<0.05)$. Curvature of the nail and pain scores decreased in all patients. Nail $\mathrm{W}$ showed a significant increase, therefore $\mathrm{H} / \mathrm{W}$ ratio decreased significantly $(\mathrm{p}<0.05)$. Although recurrence of cosmetic deformity was seen at six months, the VAS and tissue scores remained lower than preoperative values. Patients reported favorable outcomes compared to their preoperative complaints.

Conclusion: The described suture treatment method is an inexpensive, simple technique, not requiring any special material. These results support that this technique is useful for pain relief and tissue healing even if cosmetic recurrence occurs.

Keywords: Nail dystrophy, pincer nail, suture treatment.

cosmetic deformities or scar formation. On the other hand, conservative treatment modalities cause less discomfort and are well tolerated even in patients with comorbidities; however, the main concern is usually high recurrence rates. Conservative methods include chemical methods such as the application of urea pastes, and mechanical methods which usually utilize "orthonyx" materials. These are nail braces which aim to progressively flatten the nail surface by applying tension on both curved sides of the nail. ${ }^{[10]}$ Several different materials have been developed for this purpose: plastic braces glued to the nail surface, stainless steel braces and recently developed superelastic nickel-titanium wires, originally designed for orthodontic practice. ${ }^{[1-13]}$ 
Although successful outcomes have been reported with all of these special equipment, they may be expensive or unavailable for routine clinical use while necessity of long-term use reduces patient compliance. We aimed to overcome this problem by developing a less invasive treatment method, which can be easily performed without any learning curve to treat PND by using only silk sutures. ${ }^{[14]}$ Therefore, in this study, we aimed to evaluate the cosmetic and functional results of suture treatment on PND.

\section{PATIENTS AND METHODS}

This prospective study was conducted in Kütahya Health Sciences University Hospital and University of Kyrenia Hospital Orthopedics Outpatient Clinic between June 2018 and November 2018. A total of 16 nails of 13 patients ( 6 males; 7 females; mean age 46.9 years; range, 24 to 74 years) with PND were included. All patients presented to our clinic with toenail pain. All affected nails presented on big toes. All patients underwent the same procedure described before. ${ }^{[15]}$ The procedure briefly consisted of creating two holes at each side of the curved nail. Then, a silk suture was passed thorough these holes on the nail surface in a mattress manner. Beginning from plantar side, suture was passed outside-in and then inside-out through the nail. Two ends of the suture loop were passed under nail edges and pulled upwards to correct the deformity and flatten the nail. The suture was tied over the nail surface under sufficient tension to maintain the applied correction (Figure 1). No wound dressings or bandages were applied. All patients were allowed to continue routine exercises or sports activities without any restrictions. Sutures were removed under sterile conditions with povidone-iodine application at sixth week follow-up. The study protocol was approved by the University of Kyrenia Ethics Committee (RY-2018-16). A written informed consent was obtained from each patient.

The study was conducted in accordance with the principles of the Declaration of Helsinki.

All nails were examined to define morphological characteristics, such as nail cut length (shorter than the distal end of toe, at distal toe level or longer than the distal end of the toe), nail cut shape (straight or curved), and the presence of onychomycosis. Additionally, patients were questioned regarding any treatment they had received for ingrown nail or family history (Table I). The discomfort and pain of patients were documented using visual analog scale (VAS). Tissue status and level of pain was used to determine the pathologic stage, as described by Heifetz. ${ }^{[16]}$ Digital photographs were taken of each nail before treatment, at early follow-up at six weeks and final follow-up at sixth month (Figure 2). Nail height $(\mathrm{H})$ and width $(\mathrm{W})$ on the coronal plane at the distal nail tip were calculated with a ruler and also on computer software (Image J version 1.46, National Institute of Health, Bethesda, MD, USA). The H/W ratio was calculated to evaluate the curvature of the nail (Figure 3).

\section{Statistical analysis}

Mean, standard deviation, median lowest, highest, frequency and ratio values were used in the descriptive statistics of the data. The distribution of variables was measured by Kolmogorov-Smirnov test. In the analysis of the dependent quantitative data, the paired sample t-test and Wilcoxon test were used. Statistical analysis was performed using the IBM SPSS version 22.0 software (IBM Corp., Armonk, NY, USA). A $p$ value of $<0.05$ was considered statistically significant.

\section{RESULTS}

Of the seven female and six male patients with PND, eight (5 females and 3 males) had onychomycosis.

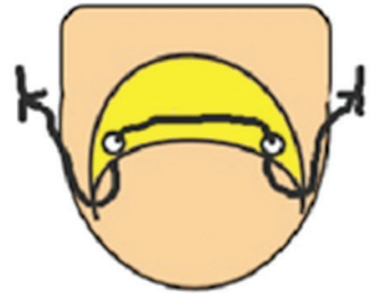

(c)

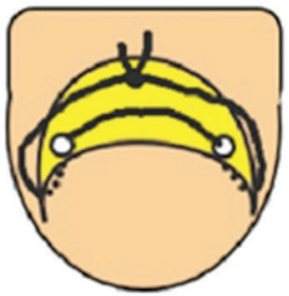

(d)

FIGURE 1. Illustration of suture technique. (a) Pincer nail deformity. (b) Creating two holes at each side of curved nail. (c) Beginning from plantar side, suture was passed outside-in and then inside-out through nail. (d) Two ends of suture loop were passed under nail edges and pulled upwards to correct deformity and suture was tied over nail surface under sufficient tension to maintain applied correction. 


\begin{tabular}{|c|c|c|c|c|c|}
\hline & $\mathrm{n}$ & $\%$ & Mean \pm SD & Median & Min-Max \\
\hline Age (year) & & & $46.9 \pm 14.9$ & 44.0 & $24.0-74.0$ \\
\hline \multicolumn{6}{|l|}{ Gender } \\
\hline Male & 6 & 46.2 & & & \\
\hline Female & 7 & 53.8 & & & \\
\hline \multicolumn{6}{|l|}{ Side } \\
\hline Right & 9 & & & & \\
\hline Left & 7 & & & & \\
\hline \multicolumn{6}{|l|}{ Finger no } \\
\hline I & 16 & 100 & & & \\
\hline \multicolumn{6}{|c|}{ Stage Heifetz } \\
\hline 0 & 1 & 6.3 & & & \\
\hline I & 2 & 12.5 & & & \\
\hline II & 13 & 81.3 & & & \\
\hline \multicolumn{6}{|c|}{ Nail cut length } \\
\hline I & 7 & 43.8 & & & \\
\hline II & 7 & 43.8 & & & \\
\hline III & 2 & 12.5 & & & \\
\hline \multicolumn{6}{|c|}{ Nail cut shape } \\
\hline Straight & 8 & 50.0 & & & \\
\hline Curved & 8 & 50.0 & & & \\
\hline \multicolumn{6}{|c|}{ Onychomycosis } \\
\hline- & 6 & 37.5 & & & \\
\hline+ & 10 & 62.5 & & & \\
\hline \multicolumn{6}{|c|}{ Ingrown nail history } \\
\hline- & 4 & 25.0 & & & \\
\hline+ & 12 & 75.0 & & & \\
\hline \multicolumn{6}{|c|}{ Treatment history } \\
\hline- & 10 & 62.5 & & & \\
\hline+ & 6 & 37.5 & & & \\
\hline \multicolumn{6}{|c|}{ Family history } \\
\hline- & 13 & 81.3 & & & \\
\hline+ & 3 & 18.8 & & & \\
\hline
\end{tabular}

Three patients presented with bilateral deformity, and two of them had a family history, suggesting the hereditary form of PND. Standard anteroposterior and lateral X-rays of all patients were obtained to exclude any underlying condition, particularly subungual exostosis. Radiographic evaluation did not show any pathological findings. Ten patients had a history of ingrown nail, five of whom were previously treated with simple nail extraction and had a recurrence. The nail cut shape and length were also evaluated. Straight and curved cut nails were equal in numbers. However, nail length was observed to be mostly short (shorter than the distal end of toe) or medium (at distal toe level); both including seven patients. Only two patients had nails longer than the distal end of the toe. No adverse events, infection or wound problems related to the suture material or the intervention were observed. One patient with onychomycosis needed a second application; at one week, the nail was split by the peripheral sutures towards the holes and both legs of the suture loop were in the same holes leading to failed tensioning. The procedure was repeated with two new holes localized more centrally and proximally.

The early postoperative at sixth weeks and the sixth month VAS score showed a significant decrease $(p<0.05)$ compared to the preoperative VAS score $(p<0.05)$ However, there was no significant difference 

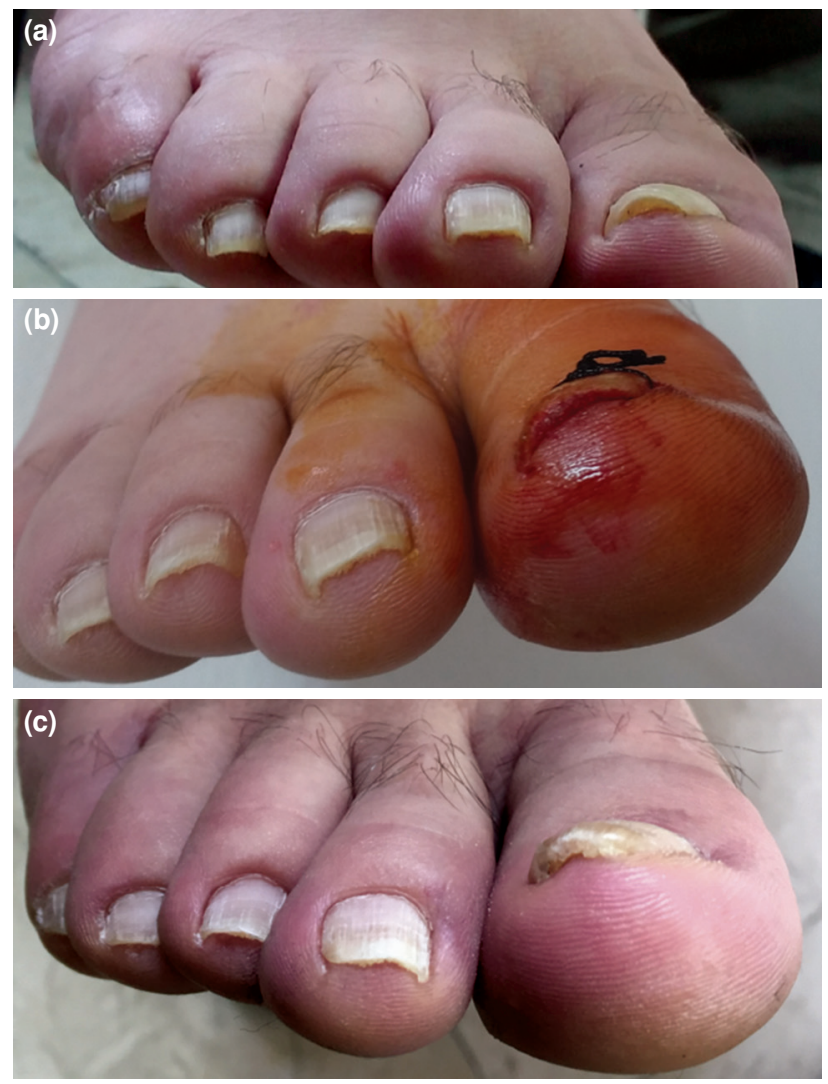

FIGURE 2. (a) Preoperative photograph of a patient's big toe with pincer nail deformity. (b) Deformity seems to improve in early postoperative period at sixth week before suture removal. (c) Final follow-up at sixth month, still improved compared to initial deformity.

between the sixth week and sixth month follow-up VAS scores ( $\mathrm{p}>0.05)$.

Both the sixth week and the sixth month follow-up severity of pain scores showed a significant decrease compared to the preoperative period $(\mathrm{p}<0.05)$. However, sixth month severity of pain score did not change significantly $(p>0.05)$ compared to sixth week values.

Nail $\mathrm{H}$ at sixth week decreased significantly $(\mathrm{p}<0.05)$ compared to preoperative period. At final follow-up, the nail $\mathrm{H}$ was found significantly increased compared to the sixth week nail $\mathrm{H}$ values, but the final nail $\mathrm{H}$ was still lower than the preoperative measurements. Nail $\mathrm{W}$ increased significantly at both postoperative sixth week and sixth month $(\mathrm{p}<0.05)$. H/W ratio, which represents the nail curve, was highest at preoperative measurements and decreased significantly at sixth week compared to preoperative values $(\mathrm{p}<0.05)$. The sixth week $\mathrm{H} / \mathrm{W}$ ratio was the lowest. The final $\mathrm{H} / \mathrm{W}$ ratio increased at sixth month compared to sixth week values while it was still significantly decreased compared to the preoperative period $(\mathrm{p}<0.05)$.

Both sixth week and sixth month tissue status decreased significantly $(\mathrm{p}<0.05)$ compared to preoperative period. There was no significant difference between sixth week and sixth month tissue status values (Tables II and Figure 4).

\section{DISCUSSION}

Pincer nail deformity is a form of nail dystrophy characterized by excessive spine of the nail plate and subsequent nail penetration in soft tissues that cause pain and discomfort. Pincer nail deformity can be seen as an inherited or acquired condition. Hereditary PND usually manifests itself with bilateral involvement and positive family history. ${ }^{[1]}$

Hereditary PND, defined as an autosomal dominant disorder, can affect other toes in addition to
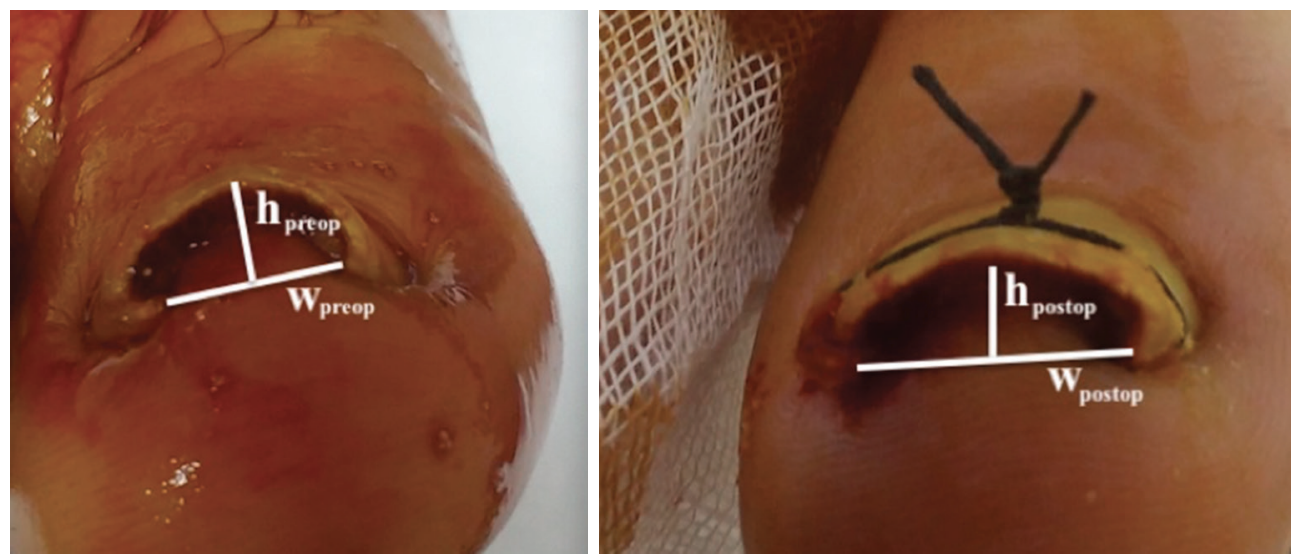

FIGURE 3. Pre- and postoperative measurement of height/width ratio.

Width $(W)$ : a parallel line to ground between two edges of pincer nail. Height $(H)$ : a perpendicular line to width line drawn from tip of nail. H/W ratio was calculated to evaluate curvature of nail. 


\begin{tabular}{|c|c|c|c|c|c|}
\hline \multicolumn{6}{|c|}{$\begin{array}{l}\text { TABLE II } \\
\text { Visual analog scale, pain severity, nail height, nail width and height/width ratio values of patients } \\
\text { preoperatively, early postoperatively and at sixth month follow-up }\end{array}$} \\
\hline & Mean $\pm S D$ & Median & Min-Max & $p^{*}$ & $p \dagger$ \\
\hline \multicolumn{6}{|c|}{ Visual analog scale } \\
\hline Preoperative & $7.38 \pm 0.96$ & 7.0 & $6.0-9.0$ & & \\
\hline Postoperative & $1.81 \pm 1.05$ & 2.0 & $0.0-4.0$ & $0.000 \ddagger$ & \\
\hline Sixth month & $2.31 \pm 1.78$ & 1.5 & $0.0-6.0$ & $0.000 \ddagger$ & $0.180 \ddagger$ \\
\hline \multicolumn{6}{|l|}{ Severity of pain } \\
\hline Preoperative & $1.94 \pm 0.57$ & 2.0 & $1.0-3.0$ & & \\
\hline Postoperative & $0.50 \pm 0.52$ & 0.5 & $0.0-1.0$ & $0.000 \ddagger$ & \\
\hline Sixth month & $0.69 \pm 0.79$ & 0.5 & $0.0-2.0$ & $0.000 \ddagger$ & $0.380 \ddagger$ \\
\hline \multicolumn{6}{|l|}{ Nail height } \\
\hline Preoperative & $108.9 \pm 34.1$ & 110.0 & $56.0-170.0$ & & \\
\hline Postoperative & $83.6 \pm 30.5$ & 76.0 & $41.0-157.0$ & $0.006 \S$ & \\
\hline Sixth month & $100.8 \pm 28.6$ & 102.5 & $55.0-163.0$ & $0.287 \S$ & $0.004 \S$ \\
\hline \multicolumn{6}{|l|}{ Nail width } \\
\hline Preoperative & $358.6 \pm 101.4$ & 340 & $174-553$ & & \\
\hline Postoperative & $404.5 \pm 90.0$ & 377 & $287-570$ & $0.122 \S$ & \\
\hline Sixth month & $431.3 \pm 92.9$ & 410 & $297-589$ & 0.010 & $0.045 \S$ \\
\hline \multicolumn{6}{|l|}{ Height/width ratio } \\
\hline Preoperative & $0.31 \pm 0.09$ & 0.27 & $0.22-0.49$ & & \\
\hline Postoperative & $0.20 \pm 0.05$ & 0.21 & $0.11-0.28$ & $0.000 \ddagger$ & \\
\hline Sixth month & $0.24 \pm 0.08$ & 0.22 & $0.13-0.42$ & $0.000 \ddagger$ & $0.004 \ddagger$ \\
\hline \multicolumn{6}{|l|}{ Tissue status } \\
\hline Preoperative & $1.00 \pm 0.37$ & 1.0 & $0.0-2.0$ & & \\
\hline Postoperative & $0.38 \pm 0.50$ & 0.0 & $0.0-1.0$ & $0.002 \ddagger$ & \\
\hline Sixth month & $0.44 \pm 0.51$ & 0.0 & $0.0-1.0$ & $0.003 \ddagger$ & $0.655 \ddagger$ \\
\hline
\end{tabular}

greater toes. Two of our patients had a positive family history for PND and, both of them had bilateral greater toe involvement; however, we did not observe any deformities on the lesser digits. A number of factors have been implicated in the pathogenesis of acquired or sporadic PND, including ill-fitting shoes, osteophytes of the first rays, osteoarthritis of the interphalangeal joint, drugs, systemic diseases, malignancies and onychomycosis; nonetheless, the main etiology for this deformity is still unclear. ${ }^{[2,3,5,17]}$ Treatment of the underlying condition may be useful for reversing the deformity, while such a related factor is not always detectable. Although all patients included in our study were questioned for these defined accompanying conditions, no factors except onychomycosis were encountered.

Onychomycosis may cause thickening of the nail, which causes the nail tips to bend. Antifungal therapy has been reported to be effective in the treatment of PND. ${ }^{[18,19]}$ More than half of our patients $(8 / 13)$ had onychomycosis. We consulted those patients with dermatology for appropriate antifungal therapy after suture application.

The procedure was more difficult in these patients due to the thicker and stiffer condition of the nail. With onychomycosis, it took more time to puncture the holes in the nails and a new needle was needed for each hole. In addition, more pulling force was required to straighten the nail tips by pulling the stitching needles. Although no significant differences were observed between nails with and without onychomycosis, antifungal therapy before intervention may be beneficial to perform the intervention more comfortably.

Pincer nail is both a cosmetic and health impairment. Some patients try to improve the appearance of the nail by rounding the nail edges, which can cause them to sink into the soft tissue at each corner of the nails. ${ }^{[20]}$ This cosmetic appearance, together with the pain and inflammation that cause the wear of the shoe, constitutes the main treatment 

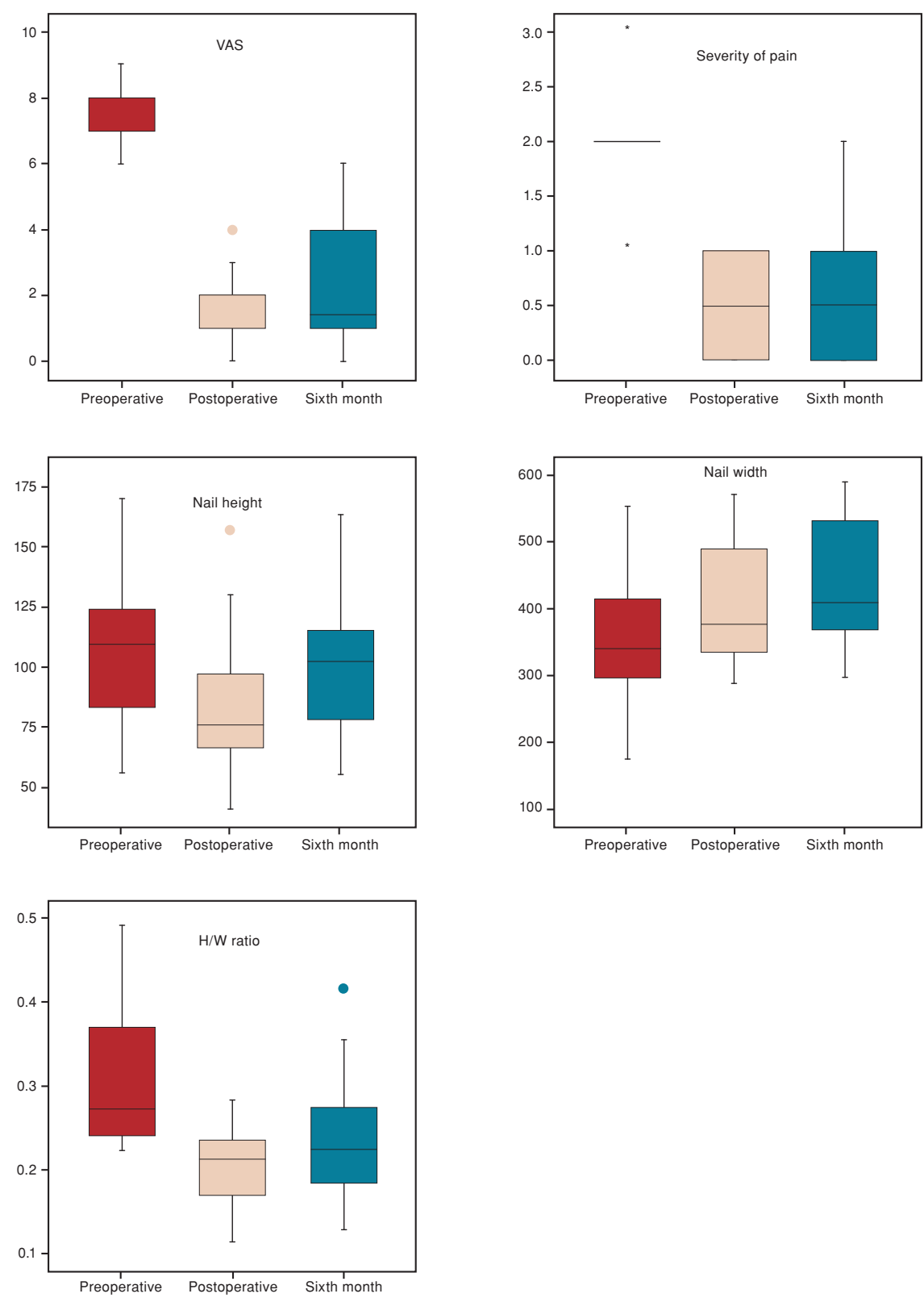

FIGURE 4. Comparison of preoperative, early postoperative and sixth month visual analog scale score, severity of pain score, nail height, nail width, and height/width ratio. H/W: Height/width; VAS: Visual analog scale.

indications for PND. Various conservative and surgical methods have been described; however, the gold standard for treatment has not yet been established. Despite these disadvantages, surgical methods that provide satisfactory long-term outcomes are generally challenging. They are often preferred for severe or recurrent deformities.

Conservative methods are well tolerated even by patients with comorbidities such as diabetes or vascular diseases. ${ }^{[21]}$ Although the risk of recurrence is high, conservative treatment modalities are preferred by most patients, considering the discomfort after surgical methods. Conservative methods may also be divided as nail grinding, static splinting and dynamic orthonyx applications.

Nail grinding is aimed at reducing the thickness of the nail by abrading the nail surface with a highspeed grinder. Although successful results have been reported, this method requires a long treatment 
period and special equipment. Dynamic orthonyx applications utilize direct forces to flatten the nail curvature. Two metal hooks on both ends of the nail connected with a twisting wire or dental string have been described. ${ }^{[17]}$ A superelastic nickel-titanium wire with strong elasticity and shape memory properties has also been successfully used for the same purpose. ${ }^{[13,22,23]}$ Instead of these devices on the market, we used silk sutures which are the cheapest suture materials that can easily be found in most facilities. Another advantage of silk suture over these metal devices is that soft suture material is more comfortable with shoe wear, and it does not require any adhesive tape or bandages to protect from socks or shoe insole. While hard metal devices may cause irritation at each side of the nail, soft silk sutures are well tolerated without discomfort.

Our study demonstrated satisfactory cosmetic outcomes at early postoperative follow-up. As the main concern for conservative treatment modalities was recurrence, we focused on defining recurrence as cosmetic and symptomatic means. Although recurrence of cosmetic deformity was seen after suture removal, the VAS, severity of pain and tissue scores remained significantly lower than preoperative values. Patients reported favorable outcomes compared to their preoperative complaints.

This study has some limitations. These are relatively short term follow-up, small number of participants and not including a randomised control group.

In conclusion, at final follow-up, the nail $\mathrm{H}$ was found to be significantly increased compared to the sixth week $\mathrm{H}$ values, while the final nail $\mathrm{H}$ was still lower than the preoperative measurements. In addition, the final $\mathrm{H} / \mathrm{W}$ ratio was still significantly decreased compared to the preoperative period. On the other hand, VAS score and severity of pain decreased significantly compared to preoperative period. These results support that this technique is useful for pain relief and tissue healing even if cosmetic recurrence occurs.

\section{Declaration of conflicting interests}

The authors declared no conflicts of interest with respect to the authorship and/or publication of this article.

\section{Funding}

The authors received no financial support for the research and/or authorship of this article.

\section{REFERENCES}

1. Chapman RS. Letter: Overcurvature of the nails--an inherited disorder. Br J Dermatol 1973;89:317-8.
2. Baran R, Broutart JC. Epidermoid cyst of the thumb presenting as pincer nail. J Am Acad Dermatol 1988;19:143-4.

3. Greiner D, Schöfer H, Milbradt R. Reversible transverse overcurvature of the nails (pincer nails) after treatment with a $\beta$-blocker. J Am Acad Dermatol 1998;39:486-7.

4. Kirkland CR, Sheth P. Acquired pincer nail deformity associated with end stage renal disease secondary to diabetes. Dermatol Online J. 2009;15:7.

5. Jemec GB, Thomsen K. Pincer nails and alopecia as markers of gastrointestinal malignancy. J Dermatol 1997;24:479-81.

6. Plusjé LG. Pincer nails: a new surgical treatment. Dermatol Surg 2001;27:41-3.

7. Haneke E. Surgical treatment of pincer nails. Dermatol Surg 2013;39:1288-9.

8. Jung DJ, Kim JH, Lee HY, Kim DC, Lee SI, Kim TY. Anatomical characteristics and surgical treatments of pincer nail deformity. Arch Plast Surg 2015;42:207-13.

9. Altun S, Gürger M, Arpacı E, İnözü E. Correction of pincer nail deformity with dermal flap: a new technique in pincer nail deformity surgery. Acta Orthop Traumatol Turc 2016;50:362-5.

10. Fraser AR. Orthonyx: theory and practice. Br J Chirop 1967;32:229-32.

11. Di Chiacchio N, Kadunc BV, Trindade de Almeida AR, Madeira CL. Treatment of transverse overcurvature of the nail with a plastic device: measurement of response. J Am Acad Dermatol 2006;55:1081-4.

12. Effendy I, Ossowski B, Happle R. Pincer nail. Conservative correction by attachment of a plastic brace. Hautarzt 1993;44:800-2.

13. Tseng JT, Ho WT, Hsu CH, Lin MH, Li CN, Lee WR. A simple therapeutic approach to pincer nail deformity using a memory alloy: measurement of response. Dermatol Surg 2013;39:398-405.

14. Atik OŞ. Every new technique either conservative or surgical is good? Eklem Hastalik Cerrahisi 2019;30:183-4.

15. Demirkıran ND. Suture treatment for pincer nail deformity: An inexpensive and simple technique. Dermatol Surg 2019.

16. Heifetz CJ. Operative management of ingrown toenail. Mo Med 1945;42:213-6.

17. Harrer J, Schöffl V, Hohenberger W, Schneider I. Treatment of ingrown toenails using a new conservative method: a prospective study comparing brace treatment with Emmert's procedure. J Am Podiatr Med Assoc 2005;95:542-9.

18. Chang P, Argueta G. Pincer nail. Our Dermatology Online 2016;7:234-7.

19. Higashi N. Pincer nail due to tinea unguium. Skin research 1990;32:40-4.

20. Baran R, Haneke E, Richert B. Pincer nails: definition and surgical treatment. Dermatol Surg 2001;27:261-6.

21. Matsumoto K, Hashimoto I, Nakanishi H, Kubo Y, Murao $\mathrm{K}$, Arase S. Resin splint as a new conservative treatment for ingrown toenails. J Med Invest 2010;57:321-5.

22. Machida E, MaruyamaK, Sano S. The correction of ingrown, curved nails with super elastic wire. J Jpn Soc Surg Foot 1999;20:S87.

23. Moriue T, Yoneda K, Moriue J, Matsuoka Y, Nakai K, Yokoi I, et al. A simple therapeutic strategy with super elastic wire for ingrown toenails. Dermatol Surg 2008;34:1729-32. 